\title{
DRUG ANALYTICAL RESEARCH
}

\author{
V. 3, n. 1, 2019
}

\section{EDITORIAL TEAM}

Martin Steppe, Faculty of Pharmacy, UFRGS (Editor-in-Chief)

Amelia T. Henriques, Faculty of Pharmacy, UFRGS

Ana Maria Bergold, Faculty of Pharmacy, UFRGS

Andreas S. L. Mendez, Faculty of Pharmacy, UFRGS

Cássia Virginia Garcia, Faculty of Pharmacy, UFRGS

Elfrides E. S. Schapoval, Faculty of Pharmacy, UFRGS

Érico M. M. Flores, Institute of Chemistry, UFSM

Herida R. Nunes. Salgado, Faculty of Pharmaceutical Sciences, UNESP - Araraquara

Isabela da Costa César, Faculty of Pharmacy, UFMG

Nadia Maria Volpato, Faculty of Pharmacy - UFRGS

Nájla M. Kassab, Faculty of Pharmaceutical Sciences, Food and Nutrition, UFMS

Tércio Paschke Oppe, Faculty of Pharmacy, UFRGS

Teresa C. T. Dalla Costa, Faculty of Pharmacy, UFRGS

Valéria Pereira de Sousa, Faculty of Pharmacy, UFRJ

\section{TECHNICAL STAFF}

Aline Argenta

Jéssica Paula S. Garcia 